\title{
Thermal Response of Space Shuttle Wing During Reentry Heating
}

Leslie Gong, William L. Ko, and Robert D. Quinn 


\section{Thermal Response of Space Shuttle Wing During Reentry Heating}

Leslie Gong, William L. Ko, and Robert D. Quinn

NASA Ames Research Center, Dryden Flight Research Facility, Edwards, California 93523

\section{N/SA}

National Aeronautics and

Space Administration

Ames Research Center

Dryden Flight Research Facility

Edwards, California 93523 
THERMAL RESPONSE OF SPACE SHUTTLE WING DURING REENTRY HEATING

\author{
Leslie Gong, * William L. Ko,** and Robert D. Quinnt \\ NASA Ames Research Center \\ Dryden Flight Research Facility \\ Edwards, California 93523
}

\section{Abstract}

A structural performance and resizing (SPAR) finite element thermal analysis computer program was used in the heat transfer analysis of the space shuttle orbiter that was subjected to reentry aerodynamic heatings. One wing segment of the right wing (WS 240) and the whole left wing were selected for the thermal analysis. Results showed that the predicted thermal protection system (TPS) temperatures were in good agreement with the space transportation system, trajectory 5 (STS-5) flight-measured temperatures. In addition, calculated aluminum structural temperatures were in fairly good agreement with flight data up to the point of touchdown. Results also showed that the internal free convection had a considerable effect on the change of structural temperatures after touchdown.

\section{Introduction}

The space shuttle orbiter reenters the earth's atmosphere at an altitude of about $121,920 \mathrm{~m}$ $(400,000 \mathrm{ft})$ and at extremely high velocity (nearly Mach 25 at the time of reentry). In order to protect the shuttle structure from severe reentry aerodynamic heating, the entire shuttle structure is covered with a thermal protection system (TPS). The regions of the shuttle surfaces receiving lower heating rates (for example, wing upper surfaces, fuselage side walls, and bay doors) are covered with highly flexible felt reusable surface insulation (FRSI), and the regions exposed to higher heating rates (for example, wing and fuselage lower surfaces) are covered with TPS tiles. A layer of highly flexible strain isolation pad (SIP) is sandwiched between the TPS tiles and the aluminum skin for absorption of the strain incompatibility between the brittle TPS tiles and the aluminum skin. Overheating of the aluminum structure may cause thermal creep resulting in the loss of structural integrity required for subsequent flights. Although the SIP layer may absorb the aluminum skin thermal buckling effect on the TPS tiles to some extent, the excess thermal buckling of the aluminum skin because of overheating could cause a debonding of TPS tiles resulting in partial or total loss of the Tps protecting functions. In former space transportation system (STS) flights the performance of the TPS was so good that the shuttle structural temperatures during reentry were kept well below the design limit temperature of $176^{\circ} \mathrm{C}\left(350^{\circ} \mathrm{F}\right)$, and thus the above mentioned concerns were practically eliminated.

\footnotetext{
* Aerospace Engineer.

**Aerospace Engineer. Member AIAA.

t Aerospace Engineer.
}

This paper is declared a work of the U.S. Government and therefore is in the public domain.
Since the shuttle is designed to be used as many as one hundred times, it is essential to understand the mechanical performance (that is, structural stress levels) under the reentry aerodynamic and thermal loadings so that confidence in the shuttle structural integrity can be established. The flight load data obtained from onboard strain gage measurements contain both the mechanical and thermal componerts. unfortunately these two components cannot be separated experimentally. In order to obtain mechanical stress, thermal stresses must be removed from the strain gage measured stresses. This can be done analytically by first calculating the thermal stresses and then removing the thermal stresses from the strain gage measured stresses to give the true mechanical stresses. To calculate the thermal stresses, the structural temperature distribution must be known. Since the number of onboard thermocouples are insufficient to accurately record the structural temperature distribution, heat transfer analysis must be performed to calculate accurate structural temperature distribution which will be used as input to a structural model for thermal stress calculations. The preliminary heat transfer analyses of typical wing cross sections were reported in Refs. 1, 2, and 3. This paper presents results of an extension of those analyses and discusses finite element heat transfer analysis of a wing segment of the right shuttle wing and the whole left shuttle wing. The results are compared with the STS-5 temperature data (the most complete set of STS flight data).

\section{Nomenclature}

$A_{\mathbf{i}}$ surface area of radiation exchange element $i$

C

capacitance matrix

$F_{i j}$

radiation view factor, or fraction of radiant heat leaving radiation element $i$ incident on radiation element $j$

FRSI felt reusable surface insulation

HRSI high temperature reusable surface insulation

JLOC joint location (grid point)

$\mathrm{K}_{\mathrm{k}}$. conduction matrix

$\mathrm{K}_{\mathbf{r}}$

radiation matrix

K21

two-node conduction element

$\mathrm{K} 31$

three-node conduction element 
K61

six-node three-dimensional conduction element

K81 eight-node three-dimensional conduction element

LRSI low temperature reusable surface insulation

$Q$

$\mathbf{R}$

RTV

R41

SIP

SPAR

STS

$\mathbf{T}$

THEOSKIN

TPS

$t$

wS

$x_{0}$

$y_{0}$

$\left[{ }^{\circ}\right]$

$[i] \quad \frac{\partial^{2}[]}{\partial t^{2}}$

$\therefore \quad \frac{\partial^{3}[]}{\partial t^{3}}$

\section{Description of problem}

Figure 1 shows the location of the wing segment WS 240 of the right shuttle wing selected for the heat transfer analysis. Ws 240 is bounded by yo 240 and yo 254 (Fig. 1). The leading edge portion of the wing and the elevon were not included in the analysis. Figure 2 shows the left shuttle wing that was analyzed. The region of the whole wing was bounded by longitudinal stations $x_{0} 1040$ and $x_{0} 1365$ (that is, elevon, glove, and leading edge regions were not included in the analysis).*

The reentry trajectory for the shuttle is shown in Fig. 3. The time was counted from the start of the reentry that occurred at an altitude

*The existing structural model for the thermal stress calculations does not include the secondary load carrying structures, elevon, leading edge regions of the wing, and the glove. Therefore, in the thermal analysis, only the major load carrying structures were modeled. of $121,920 \mathrm{~m}(400,000 \mathrm{ft})$. The nominal (or designed) trajectory is shown with solid curves, and data points were obtained from the space transportation system, trajectory 5 (STS-5) flight. The trajectories for STS-1 through STS-4 are similar to the sTS-5 flight trajectory and, therefore, are not shown.

The calculation of the reentry aerodynamic heating was based on the actual STS-5 flight trajectory. The STS-5 flight was chosen because it provided the most complete set of flight data compared with other sTs flights in which some of the flight data were lost.

\section{Description of wing structures}

As shown in Fig. 2, the ribs of the wing are fabricated with vertical and diagonal trusses. All of the spar webs and the wheel well vertical walls are made of corrugated aluminum skins. Both the lower and upper wing skins lying between $x_{0} 1191$ and $x_{0} 1365$ are made of hat-stringerreinforced aluminum panels. The lower and upper wing skins lying between $x_{0} 1040$ and $x_{0} 1191$, and the leading edge beam assembly are made of aluminum honeycomb-core-reinforced sandwich panels. The landing gear door is made of double-walled, hat-stringer-reinforced aluminum panels separated by aluminum stringers. The entire lower wing is covered with high temperature reusable surface insulation (HRSI) tiles, with a layer of SIP lying between the wing skin and the HRSI for absorption of thermal strain incompatibility between the wing skin and the HRSI. Most of the upper skin near the leading edge region is covered with low temperature reusable surface insulation (LRSI) tiles. A SIP layer lies undex the LRSI. The rest of the upper wing skin, which is subject to low heating, is covered with FRSI under which there is no SIP layer. The room temperature vulcanized (RTV) rubber bonding agent was used in bonding the TPS and SIP to the substructures. Some of the gaps between the TPS tiles in the high temperature areas were filled with ceramic coated alumina mat (gap fillers) to prevent hot gases from coming in contact with the substructure at the bottom of each gap. Figure 4 shows the structural details of the wing segment ws 240 of the right shuttle wing.

\section{Thermal Modelings}

\section{Structural simplifications}

Because of the complex nature of the shuttle structure, some structural simplifications were required before setting up thermal models so that the analysis would be manageable using existing computers. Excessively detailed models could lead to tedious radiation-view-factor computations, in which the gain in solution accuracies may not be as much compared with the solution obtained from simplex, yet reasonably detailed models. In order to examine the adequacy of representing the hatstringer-reinforced skins with smooth skins of uniform equivalent thicknesses, the conventional finite difference method was used in the twodimensional heat transfer analysis of a single hat-stringer. As shown in Fig. 5, the hat-stringer that was analyzed was located at the lower skin of WS 240, bay 3. The upper skin, the spar webs, and the lower skin - excluding the hat stringer were assumed to have uniform thicknesses. In the 
analysis, all types of radiation heat exchanges were considered: (1) external radiation from the TPS surface into space; (2) radiation exchanges between the hat-stringer outer surface and the inner surface of the bay; and (3) internal radiation inside the hat stringer. The heat input was based on that used on Mission 3. The calculated temperatures in Fig. 6 show the peak temperature difference between points $A$ and $B$ to be about $14.44^{\circ} \mathrm{C}\left(26^{\circ} \mathrm{F}\right)$. The temperature curves for the case where there was no internal radiation within the hat stringer is almost identical to corresponding temperature curves in which the hat-stringer internal radiation was considered. This suggests that the effect of the hat-stringer internal radiation is negligible. Because the temperature differences between points $A$ and $B$ of the hat stringer were small, in the finite element modeling, the hat stringer, corrugated spar webs, wheel well walls, and honeycomb-core sandwich panels were represented by smooth solid panels of equivalent thicknesses having isotropic thermal conductivities.

\section{Finite Element Modelings}

A structural performance and resizing (SPAR) finite element thermal analysis computer program (Ref. 4) was used for the reentry heat transfer analysis of the space shuttle orbiter.

wing segments. The SPAR finite element model setup for the wing segment WS 240 is shown in Fig. 7. The model is three-dimensional and has 920 joint locations (JLOCs). The wing skins, spar webs, rib cap shear webs, RTV layers (lying on both sides of the SIP), and the TPS surface coatings were modeled with $\mathrm{K} 41$ elements (four-node heat conduction elements). The spar caps, rib caps, and the rib trusses were modeled with $\mathrm{k} 21$ elements (two-node heat conduction elements). The TPS was modeled in 10 layers on the lower surface, and 3 to 4 layers on the upper surface using K81 elements (eight-node three-dimensional heat conduction elements) and $\mathrm{k} 61$ elements (six-node threedimensional heat conduction elements). The $\mathrm{K} 61$ elements were used only in the region where the modeled TPS layers changed from four to three layers on the bay 1 upper surface (see Fig. 7). The SIP was modeled with only one layer of $\mathrm{K} 81$ elements. The aerodynamic surfaces were modeled using one layer of $\mathrm{K} 41$ elements of unit thickness to provide source heat generation. The external and the internal radiations were handled by attaching a layer of $\mathrm{R} 41$ elements (four-node radiation elements) to the radiation surfaces. The radiation into space was modeled by one R41 element. No radiation elements were attached to the surfaces of the rib cap shear webs and the rib trusses because of small exposed areas. The front and rear ends of the model were totally insulated.

Because of the existence of the gaps between the TPS tiles HRSI and LRSI, the heat flow through the TPS tiles was restricted only in the tile thickness direction for the thermal models mentioned above. In the analysis, two thicknesses were used for the HRSI and LRSI tiles: 100-percent and 80-percent TPS thicknesses. The purpose of using the effective thickness of 80 percent of the original TPS thickness was to account for the gap heating between the TPS tiles. The effect of internal natural convective heat transfer was not considered. * The effect of the forced convective cooling on the structural temperatures prior to touchdown was found to be negligible and, therefore, was not considered for the wing thermal models except the wS 240 .

Whole wing. The SPAR thermal model (called WING model) set up for the whole left shuttle wing is shown in Fig. 8. This wing model was patterned after existing structural models. The entire WING SPAR thermal model has 2289 joint locations. Because of the exsistence of gaps between the TPS tiles, HRSI and LRSI, and because of the thinness of both FRSI and SIP layers, the heat flow through TPS and SIP was assumed to be one-dimensional in thickness direction. Thus the TPS for the lower surface was modeled in five layers with $\mathrm{K} 21$ elements, and the TPS for the upper surface was modeled in three layers with K21 elements. Using K21 elements was found to be more efficient (with respect to computation time) than using $\mathrm{K} 81 \mathrm{ele-}$ ments and restricting the heat flow to one direction. The SIP layer was modeled with only one layer of K21 elements. The rib trusses and the rib and spar caps were modeled with $\mathrm{K} 21$ elements. All of the aluminum skins, the corrugated spar webs, the wing root wall (fuselage wall), and the wheel well walls were modeled with $\mathrm{K} 31$ and $\mathrm{K} 41$ elements. The aerodynamic surfaces were modeled with one layer of $\mathrm{K} 41$ elements of unit thickness for source heat generation. The internal and external radiation effects were handled by attaching $R 31$ (three-node radiation elements) and $R 41$ elements at the radiation surfaces of the aluminum skins and the TPS. The wing root vertical wall and the vertical boundary walls of the wing were completely insulated. The radiation into space was modeled with only one R41 element which was kept at a constant temperature of $26.7^{\circ} \mathrm{C}\left(80^{\circ} \mathrm{F}\right)$. The effect of natural convection inside the wing was not considered.

There were three purposes for setting up the WING SPAR thermal model for the whole wing. The first was to generate the temperature distribution required for input to the existing whole wing SPAR structural model for the calculations of thermal stresses. The second was to compare the predictions with those based on wing segment models. The third purpose was to examine the adequacy of the wing model because it was recognized that the WING model was not fine enough to define temperature gradients near spars and ribs. The reason for using coarser elements for the whole wing model compared with those used for the wing segment model was to match the existing structural model for the whole wing and to limit the effort in the computations of view factors for the threedimensional radiation exchanges inside the wing.

\section{Aerodynamic Heating}

The external heat inputs to the thermal models were computed by a NASA computer program called theoretical skin heating (THEOSKIN) which uses the velocity-altitude-angle-of-attack time history of

**At the time of this writing, the capability of handling two-dimensional free convection is being introduced to the SPAR program. 
the flight-measured sts-5 trajectory given in Fig. 3. The THEOSKIN program solves the onedimensional thin skin heating equation and computes time histories of surface temperatures, heating rates, heat transfer coefficients, and skin friction. The thermodynamic and transport properties of air used in this analysis are given in Ref. 5 .

Representative heating rates for WS 240 are presented in Fig. 9. The heating rates for the lower surface were computed assuming laminar flow up to $1160 \mathrm{sec}$ and turbulent flow from $1160 \mathrm{sec}$ until the end of the flight. The laminar heat transfer was computed by relating heat transfer to a skin-friction equation through a modified Reynolds analogy. In this analysis, the Blasius incompressible skin friction equation was related to heat transfer by the prandtl number to the negative six-tenth power. ${ }^{6}$ Compressibility effects were accounted for by using Eckerts' reference enthalpy transformation. 7 Details of this method for calculating heat transfer at hypersonic speeds are given in Ref. 8. The turbulent heat transfer was computed by a similar procedure except that the van Driest transformation was used to account for compressibility, and the Reynolds analogy factor was assumed to be a constant value of $1.1 .9,10$

The boundary layer flow on the upper surface of bay 1 at WS 240 was assumed to be attached. The rest of the upper surface of the wing was assumed to be in a region of separated flow. The heat transfer for the attached flow areas was computed using the same heat transfer codes that were used to calculate the lower surface heating. To calculate the heating rates for the separated flow areas on the upper surface, the heat transfer codes were empirically modified. The empirical corrections that were used were determined from comparisons with previous measured flight data.

The heating rates for the whole wing were generated from calculations made for WS 240 and other wing segments through linear interpolations and extrapolations.

\section{Radiation Exchange}

For both the external and the internal thermal radiation exchanges, all of the view factors were calculated from the equation

$$
A_{i} F_{i j}=A_{j} F_{j i}
$$

where $A_{i}$ is the surface area of radiation exchange element $i$, and $F_{j i}$ is the view factor, defined as the fraction of radiant heat leaving element $j$ incident on element i.11 In the calculation of view factors for the external radiation exchanges (considering that element $i$ represents the space element and element $j$ any radiation exchange element on the wing or fuselage surface), $F_{j i}$ was taken to be unity; therefore, $F_{i j}=A_{j} / A_{i}$ according to Eq. (1). Values of emissivity and reflectivity used to compute radiant heat fluxes were:

\begin{tabular}{lcc}
\multicolumn{1}{c}{ Surface } & Emissivity & Reflectivity \\
\cline { 2 - 3 } Windward & 0.850 & 0.150 \\
Leeward & 0.800 & 0.200 \\
Internal structure & 0.667 & 0.333 \\
Space & 1.000 & 0
\end{tabular}

The initial temperature distribution used in the analysis was obtained from the actual flight data. In thermal modeling, the majority of the time was consumed in the computations of view factors.

\section{Transient Thermal Solutions}

The SPAR thermal analysis finite element computer program was used in the calculation of temperature time histories at all joint locations of the thermal models. The SPAR program used the approach described below to obtain transient thermal solutions.

The transient heat transfer matrix equation

$$
\left(K_{k}+K_{r}\right) T+\dot{C T}=Q+R
$$

where

$$
\begin{aligned}
\mathrm{K}_{\mathrm{k}} & =\text { conduction matrix } \\
\mathrm{K}_{\mathbf{r}} & =\text { cadiation matrix } \\
\mathrm{T} & =\text { temperature } \\
\mathrm{C} & =\text { capacitance matrix } \\
{[} & =\frac{\partial[\mathrm{I}}{\partial \mathrm{t}} \\
\mathrm{Q} & =\text { source load vector } \\
\mathrm{R} & =\text { radiation load vector } \\
\mathrm{t} & =\text { time }
\end{aligned}
$$

was integrated by assuming that the temperature vetor $\mathrm{T}_{i+1}$ at time step $t_{i+1}$ can be expressed as

$$
\mathrm{T}_{i+1}=\mathrm{T}_{\mathrm{i}}+\dot{\mathrm{T}}_{\mathrm{i}} \Delta \mathrm{t}+\frac{1}{2 !} \ddot{\mathrm{T}}_{\mathrm{i}} \Delta \mathrm{t}^{2}+\frac{1}{3 !} \ddot{\mathrm{T}}_{\mathrm{i}} \Delta \mathrm{t}^{3}+\ldots
$$

where

$$
\begin{aligned}
& \ddot{[j]}=\frac{\partial^{2}[]}{\partial t^{2}} \\
& \therefore \bar{i}=\frac{\partial^{3}[1]}{\partial t^{3}}
\end{aligned}
$$

and $T_{i}$ is the temperature vector at time step $t_{i}$ and $\Delta t$ is the time increment. The vector $\dot{T}_{i}$ is determined directly from Eq. (2); that is,

$$
\dot{\mathrm{T}}_{\mathrm{i}}=-\mathrm{C}^{-1}\left(\mathrm{~K}_{\mathrm{k}}+\mathrm{K}_{\mathrm{r}}\right) \mathrm{T}_{\mathrm{i}}+\mathrm{C}^{-1}(Q+R)
$$

Higher-order derivatives are obtained by differentiating Eq. (2) accoraing to the assumption that (1) material properties are constant over $\Delta t$, (2) Q varies linearly with time, and (3) $R$ is constant over $\Delta t$. For example,

$$
\begin{aligned}
& \ddot{\mathrm{T}}_{\mathrm{i}}=-\mathrm{C}^{-1}\left(\mathrm{~K}_{\mathrm{k}}+4 \mathrm{~K}_{\mathrm{r}}\right) \dot{\mathrm{T}}_{\mathrm{i}}+\mathrm{C}^{-1} \dot{\mathrm{Q}} \\
& \ddot{\mathrm{T}}_{\mathrm{i}}=-\mathrm{C}^{-1}\left(\mathrm{~K}_{\mathrm{k}}+4 \mathrm{~K}_{\mathrm{r}}\right) \ddot{\mathrm{T}}_{\mathrm{i}}+4 \dot{\mathrm{K}}_{\mathrm{r}} \dot{\mathrm{T}}_{\mathrm{i}}
\end{aligned}
$$

In the present computations, the Taylor series expansion ( $\mathrm{Eq} .(3)$ ) was terminated after the third term. The pressure dependency of the TPS and SIP thermal properties was converted into time dependency based on the trajectory given in Fig. 3. Time-dependent properties were averaged over "time intervals" (RESET TIME) which were taken to be 2 or $25 \mathrm{sec}$. Temperature-dependent properties were evaluated at the temperatures computed at the beginning of each time interval. $Q, \dot{Q}$, and $R$ were computed every 2 sec. 
Results

TPS Surface Temperatures

Figures 10 to 13 show the locations and numbers of thermocouples at the TPS surfaces and the aluminum skins.

In Fig. 14 the STS-5 flight-measured TPS surface temperatures are compared with the calculated values at the wing cross section $y_{0} 240$. The agreements are quite good, indicating that the calculations of the aerodynamic heatings were accurate. In a narrow time range of $t=1500$ to $2000 \mathrm{sec}$ (immediately before and after the touchdown time), the flight data, especially for the lower TPS surfaces, showed temperatures lower than the calculated temperatures. This discrepancy could be caused by insufficient forced convective coolings in the heat input calculations and the neglect of internal free convection resulting primarily from the entering of cool air into the shuttle.t Results showed that use of the forced convective cooling near the touchdown time (negative heating) resulted in excess computation time because of the change of sign in heat input, and that the effect of using negative heating on the structural temperatures was almost pictorically inconspicuous. Therefore, negative heating was not included in the thermal analyses of the whole wing. The flight data for the lower TPS surface of WS 240 , bay 3 contain void data as indicated, because the lower limits of the thermocouple temperature readouts were set too high.

\section{Structural Temperatures}

Figure 15 shows the calculated aluminum skin temperatures at typical points of WS 240, compared with the STS-5 flight data. For the wing segment, the temperature calculations made were based on 80-percent TPS thickness (solid lines) and 100percent TPS thickness (dashed lines). For the whole wing, 100-percent TPS thickness was used in the temperature calculations. For WS 240 (Fig. 15), the measured lower skin temperature data follows fairly close to the calculated tempexature curves based on 100-percent TPS thickness up to almost touchdown time; after that the flight data continued to show lower temperatures. The structural. temperatures calculated from the wing segment model WS 240 (100-percent TPS thickness) and from the WING model are quite close. The marked discrepancies between the calculated and the measured lower skin temperature after touchdown could be caused by the effects of free convective cooling and the entering of cool air into the wing. The effect of free convections was not considered in the analysis because at the time of the analysis, the SPAR program was still incapable of handling free convective heat transfer. For the upper skin of $y_{0} 240$, the measured and the calculated temperatures (based on 100-percent TPS thickness) compare reasonably well even after the touchdown. The agreement was especially good for the bay 1 upper skin.

tAir enters the interior of the shuttle orbiter at an altitude of $30,048 \mathrm{~m}(100,000 \mathrm{ft})$ (about $1400 \mathrm{sec}$ from reentry).
Figure 16 shows the chordwise distributions of aluminum skin temperatures for the reentry time of 1600 sec for WS 240. The "scalloped" shape reflects the drop in temperature at the heat sinks (that is, spar caps). The scalloped distributions of the skin temperatures are a direct correlation to the degree of thermal stress buildups in the structure. The STS-5 flight data correlate reasonably well with the predictions except for a few data points.

\section{Conclusions}

The structural performance and resizing (SPAR) finite element computer program was used in the reentry heat transfer analysis of one wing segment and the whole left wing of the space shuttle orbiter. The SPAR finite element thermal models were set up in three dimensions. The results of the thermal analysis showed that:

1. The predicted thermal protection system (TPS) surface temperatures agree quite well with the flight measured data.

2. The measured and predicted structural temperatures correlate fairly well prior to touchdown. This implies that the SPAR thermal models set up for both the wing and the wing segment were adequate.

3. The internal free convection has considerable effect on the structural temperatures after touchdown and cannot be ignored.

4. The effect of the internal radiation was found to be significant and cannot be ignored even at the relatively low structural temperatures. The view factor computations for the internal radiation resulted in a major task in thermal modeling; therefore, capability of view factor computations internally in the SPAR program is highly recommended.

5. Although the finite elements used in the SPAR WING model are relatively coarse, the thermal model gives fairly good structural temperature predictions. Thus the structural temperature distribution obtained from the WING model could be used with confidence for input to the whole wing SPAR structural model for thermal stress calculations.

6. The SPAR WING thermal model gives only coarse structural temperature distribution for the overall estimation of thermal stresses in the whole wing. For the detailed local thermal stress calculations, the wing segment models give better solutions.

\section{References}

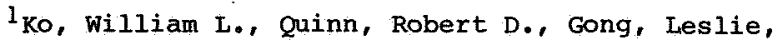
Schuster, Lawrence S., and Gonzales, David, "Preflight Reentry Heat Transfer Analysis of Space Shuttle," AIAA Paper 81-2382, Nov. 1981.

${ }^{2}$ Ko, William L., quinn, Robert D., Gong, Leslie, Schuster, Lawrence S., and Gonzales, David, "Reentry Heat Transfer Analysis of the space shuttle orbiter," Computational Aspects of Heat Transfer in structures, NASA CP-2216, 1982, pp. 295-325. 
${ }^{3}$ Gong, Leslie, Quinn, Robert $D_{2}$, and Ko, William L., "Reentry Heating Anaylsis of space Shuttle with Comparison of Flight Data." Computational Aspects of Heat Transfer in structures, NASA CP-2216, 1982, $p p_{*} 271-294$.

${ }^{4}$ Marlowe, M. B. Moore, R. A, and Whetstone, W. D., "SPAR Thermal Analysis processors Reference Manual, System Level 16. Volume 1: Program Execution," NASA CR-159162, 1979.

${ }^{5}$ Hansen, C. Frederick, "Approximations for the Thermodynamic and Transport properties of HighTemperature Air," NASA TR R-50, 1959.

${ }^{6}$ Schlichting, H., Boundary-Layer Theory, 4th ed., McGraw-Hill Book Co., 1960.

${ }^{7}$ Eckert, Ernest R. G., "Survey of Boundary Layer Heat Transfer at High Velocities and High
Temperatures," WADC TR-59-624, Wright Air Dev。 Center, U.S. Air Force, Apr. 1960.

B Zoby, E. V., Moss, J. N., and Sutton, K., "Approximate Convective-Heating Equations for Hypersonic Flows," J. Spacecraft and Rockets, vol. 18, Jan. 1981, pp. 64-70.

9 van Driest, E. R., "The Problem of Aerodynamic Heating," Aeronaut. Eng. Rev., vol. 15, no. 10, oct. 1956, pp. 26-41.

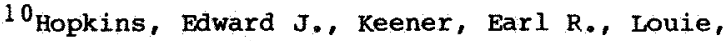
pearl T., "Direct Measurements of Turbulent Skin Friction on a Nonadiabatic Flat Plate at Mach Number 6.5 and Comparisons with Eight Theories," NASA TN D-5675, 1970.

$11_{\text {Sparrow, E. M. and Cess, R. D., Radiation }}$ Heat Transfer, McGraw-Hil1 Book Co., 1978 .

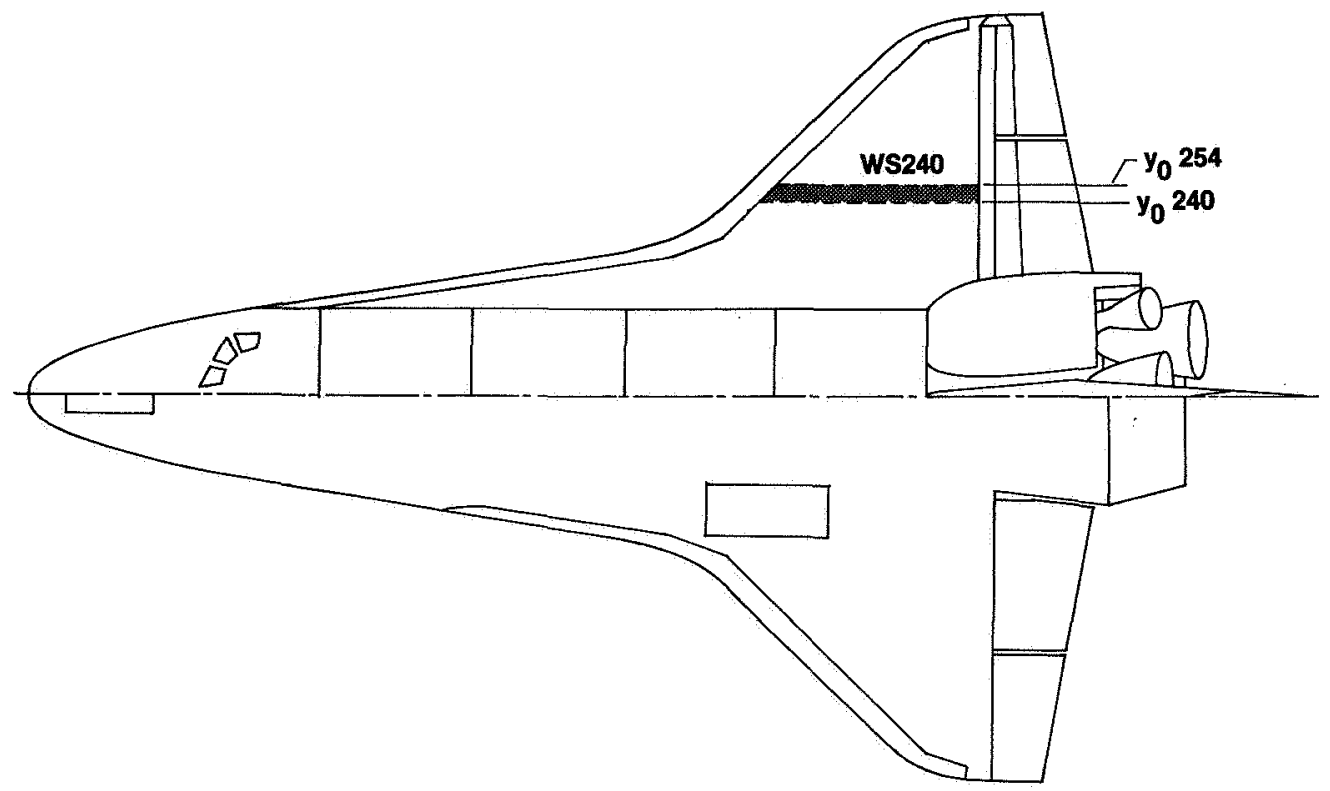

Fig. I Locations of space shuttle wing segment that were analyzed. 


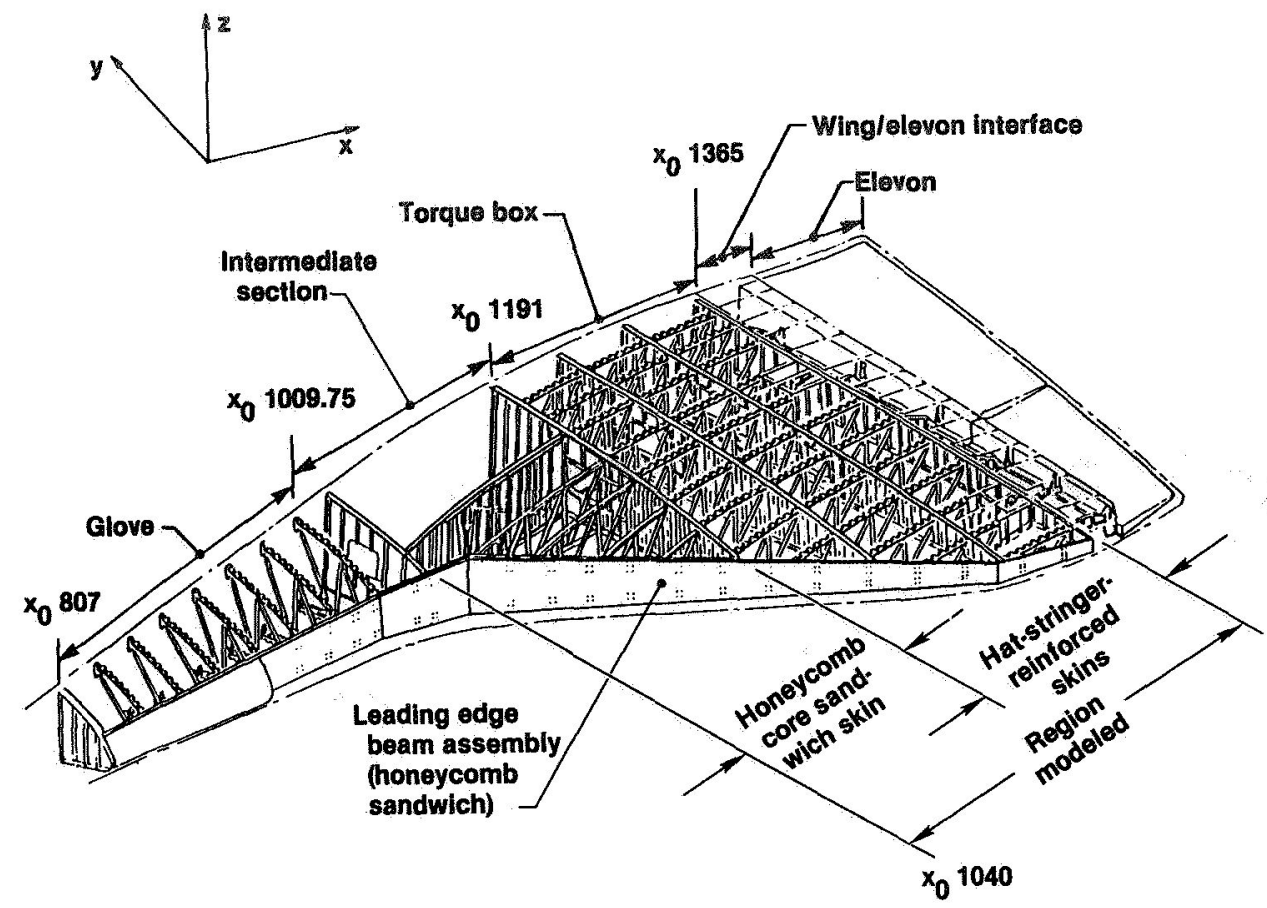

Fig. 2 Space shuttle left wing.

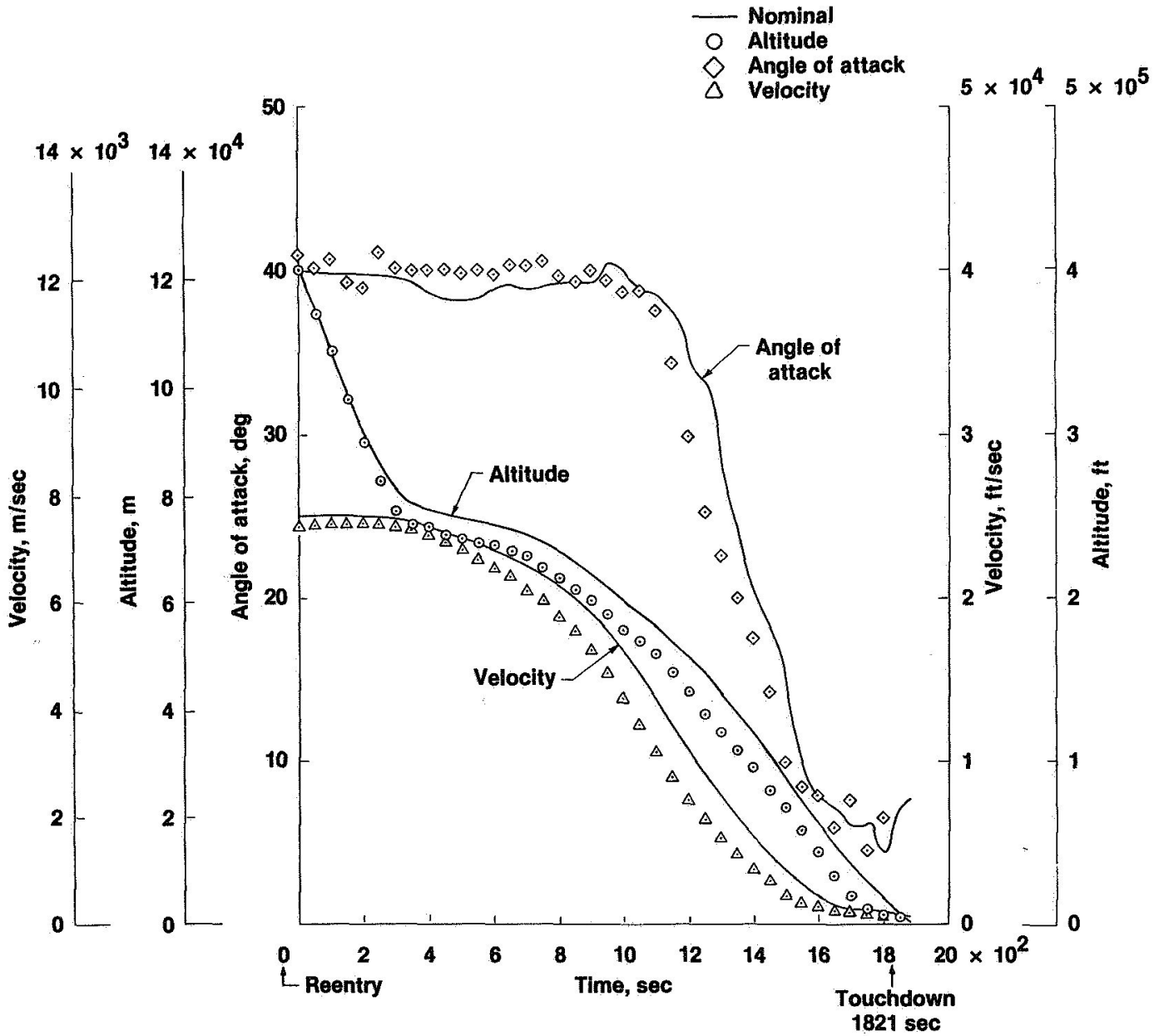

Fig. 3 STS-5 reentry trajectory. 


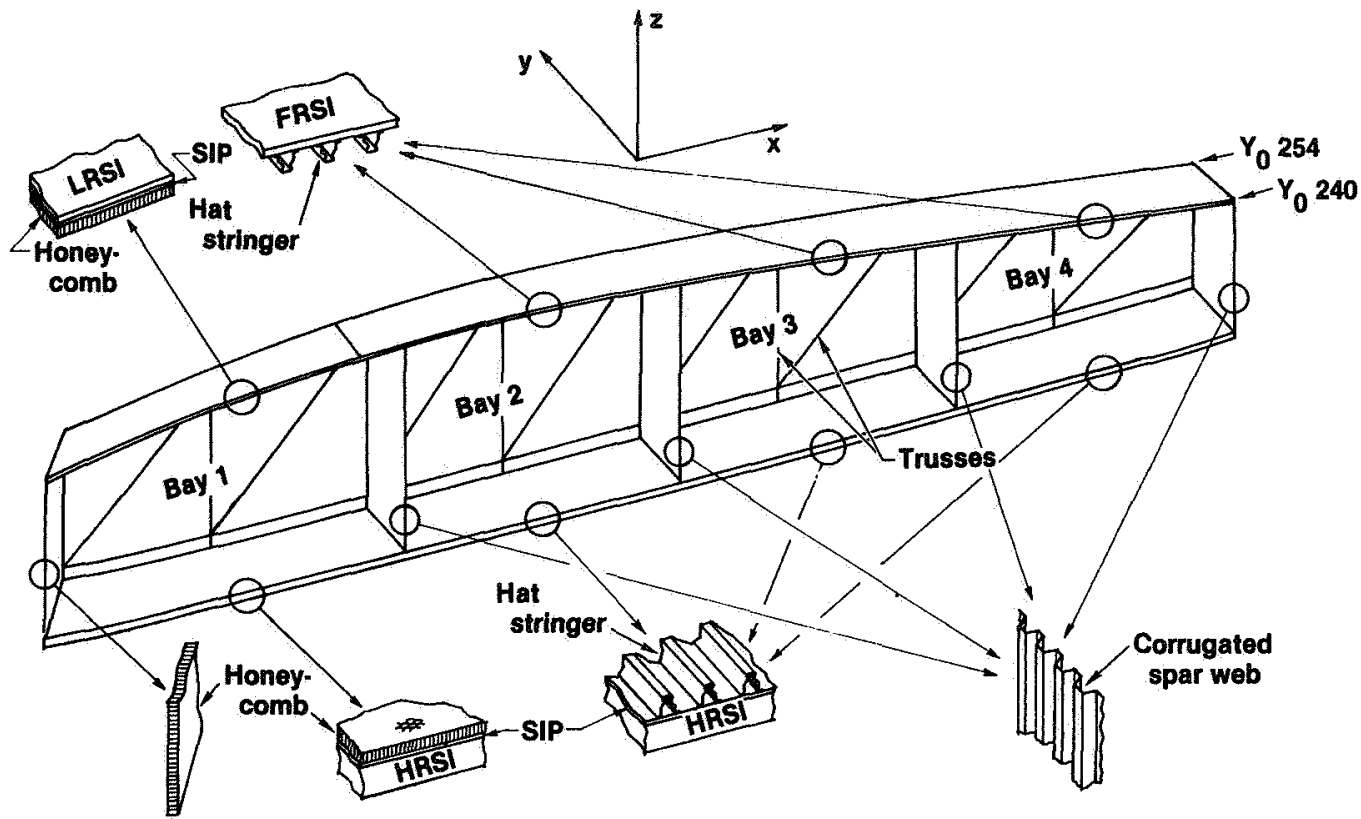

Fig. 4 Geometry of a wing segment between $Y_{O} 240$ and $Y_{O} 254$.

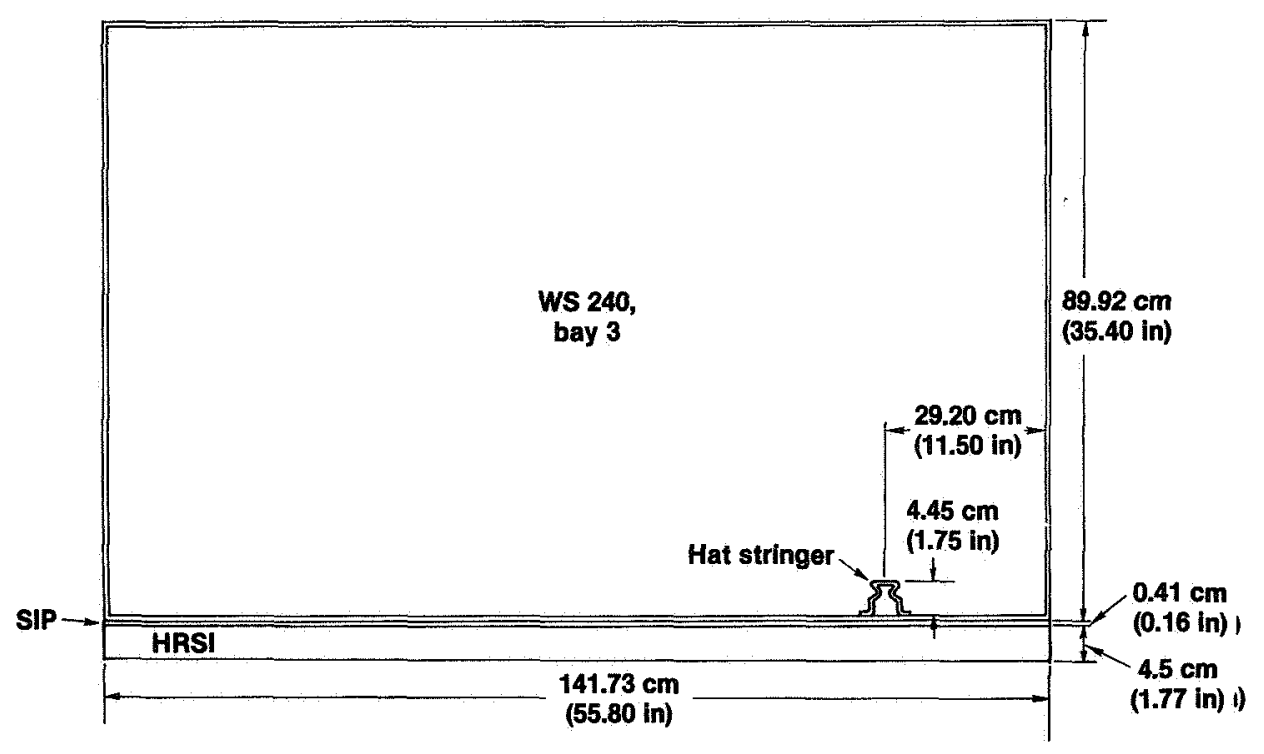

Fig. 5 WS 240 , bay 3 with one hat stringer. 


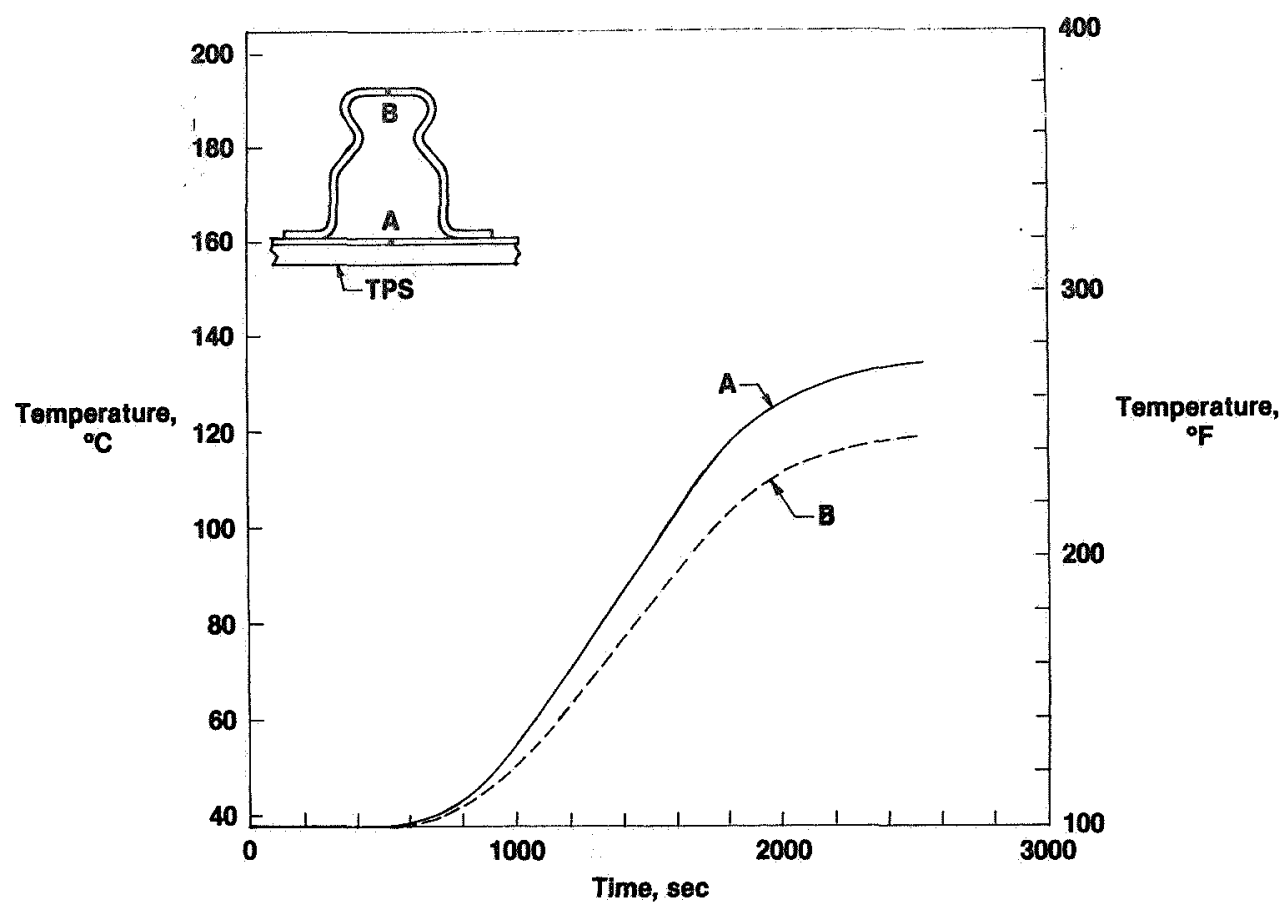

Fig. 6 Temperature time histories at points in hat-stringer mission 3 heating.

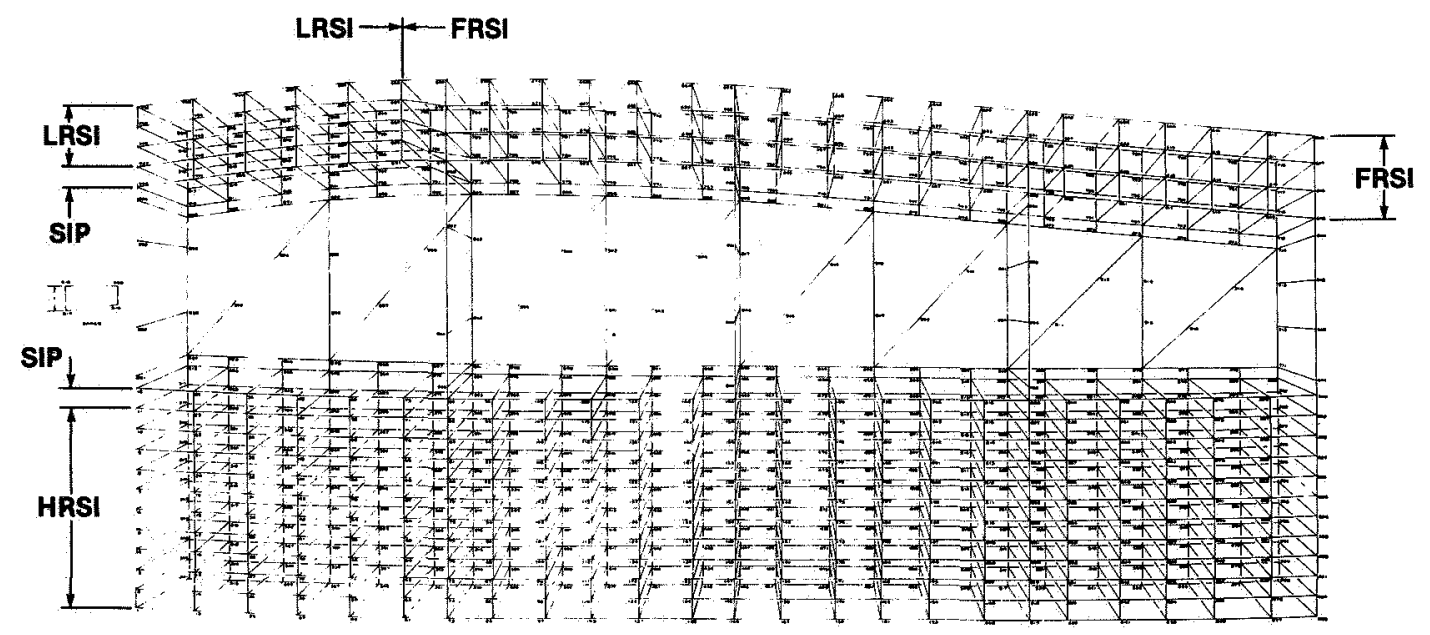

Fig. 7 Three-dimensional SPAR finite element thermal model for WS 240 (920 joint locations).

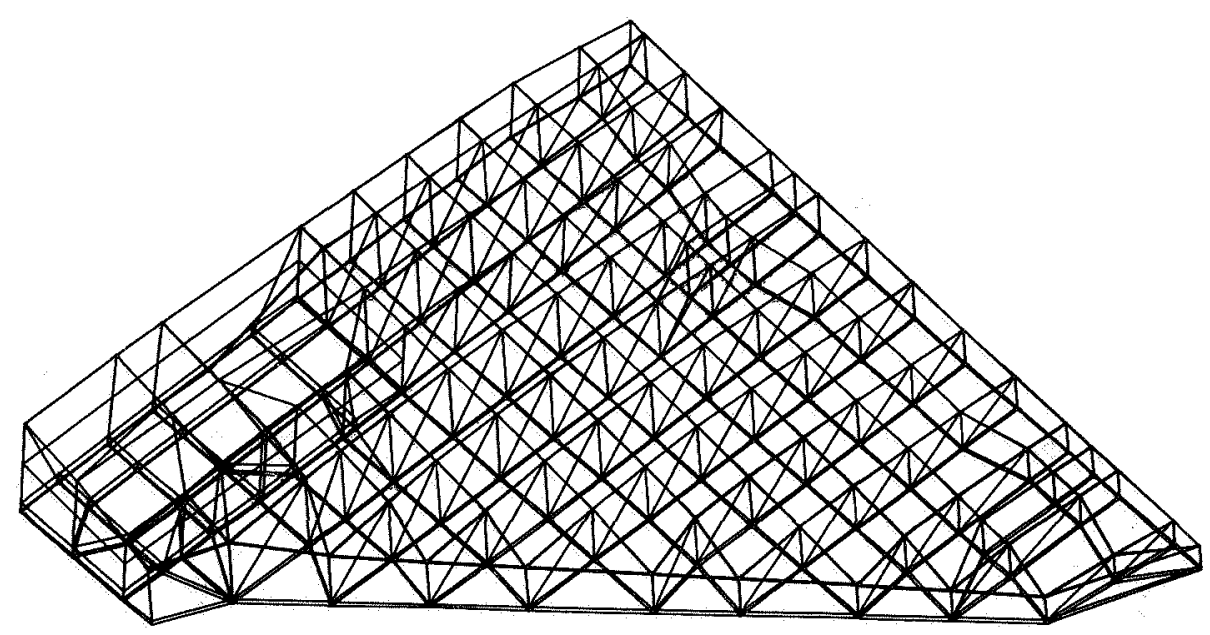

Fig. 8 Space shuttle wing SPAR thermal model (2289 joint locations). 


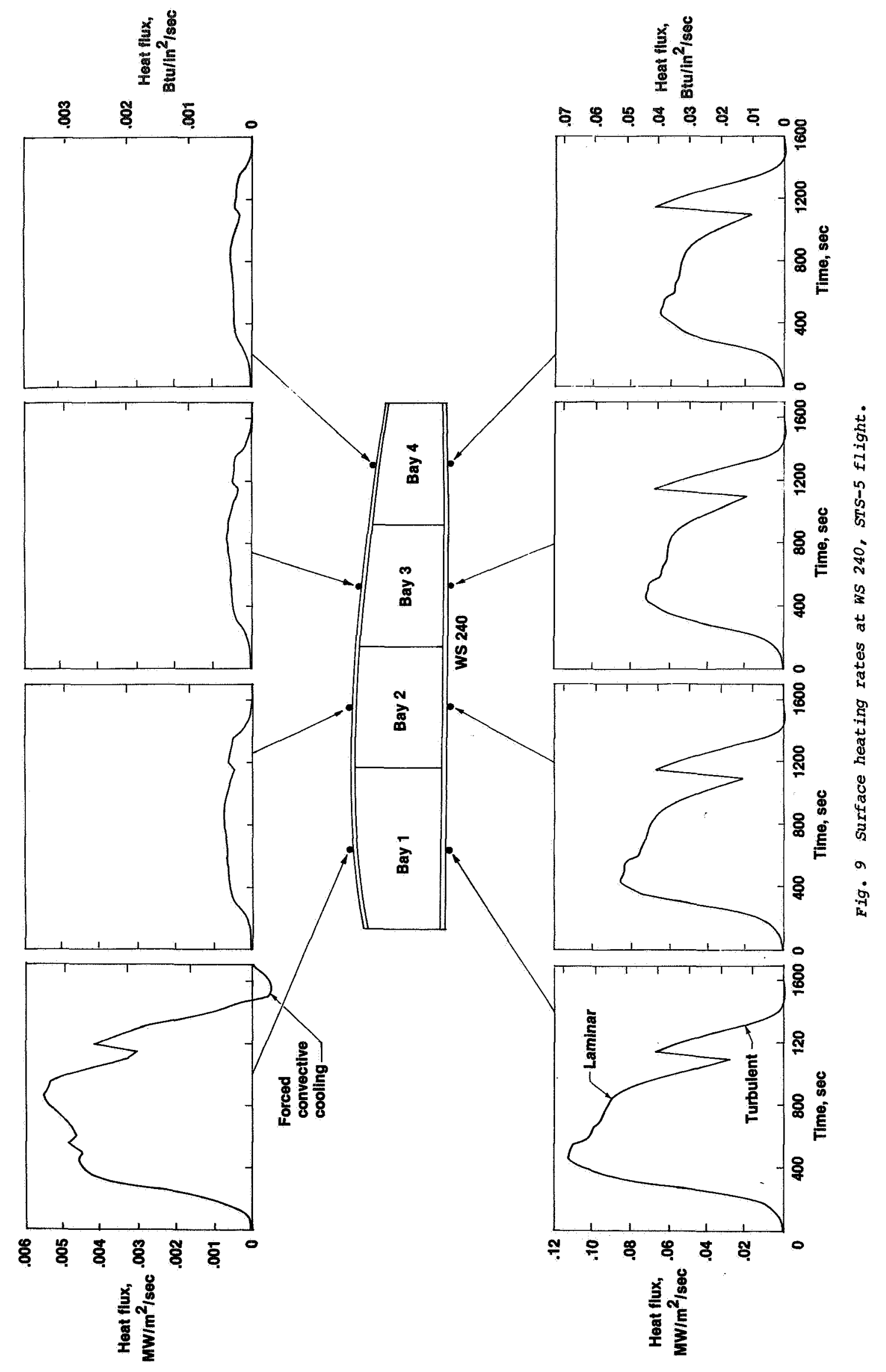




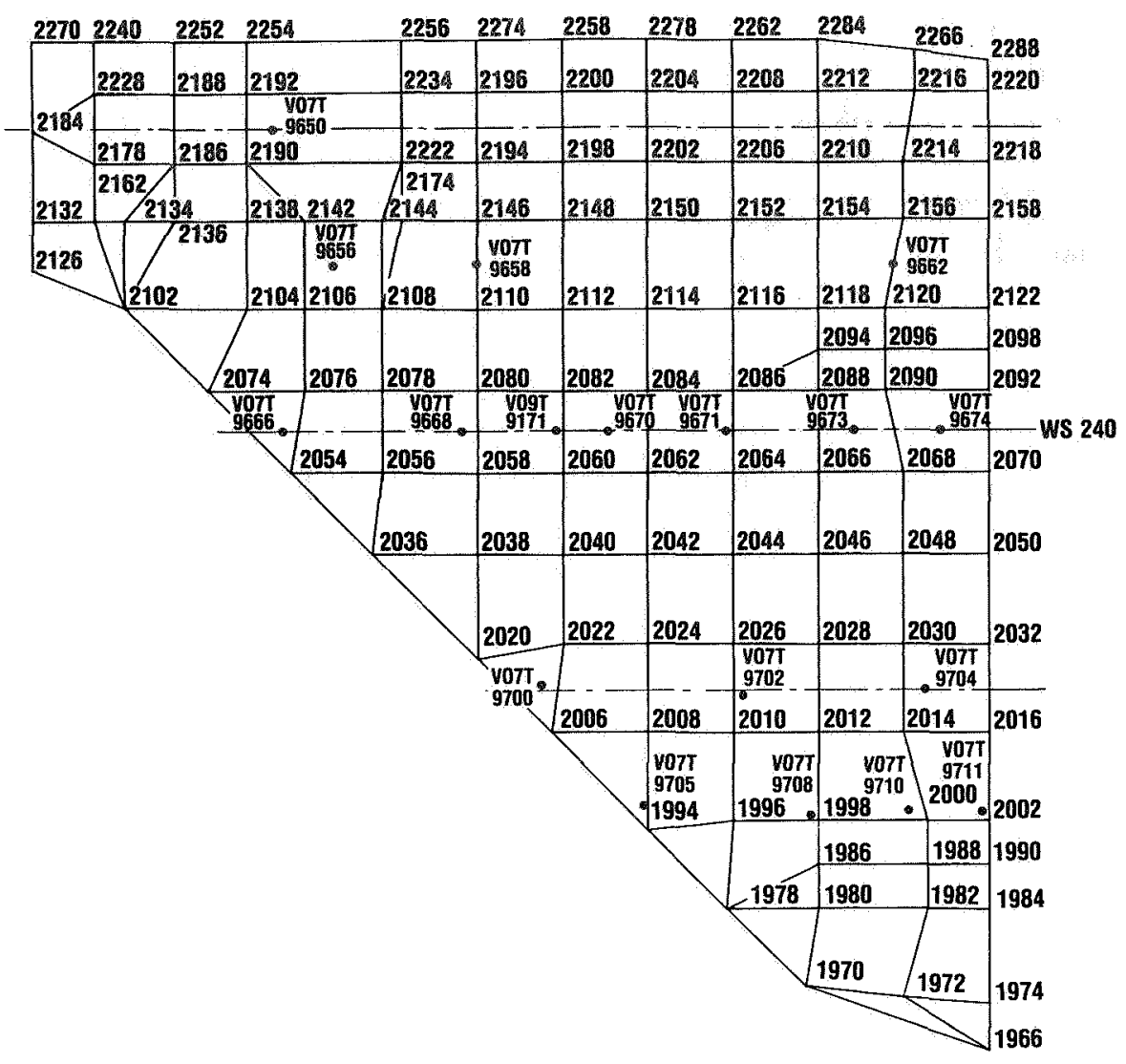

Fig. 10 wing lower TPS surface joint locations and thermocouple locations.

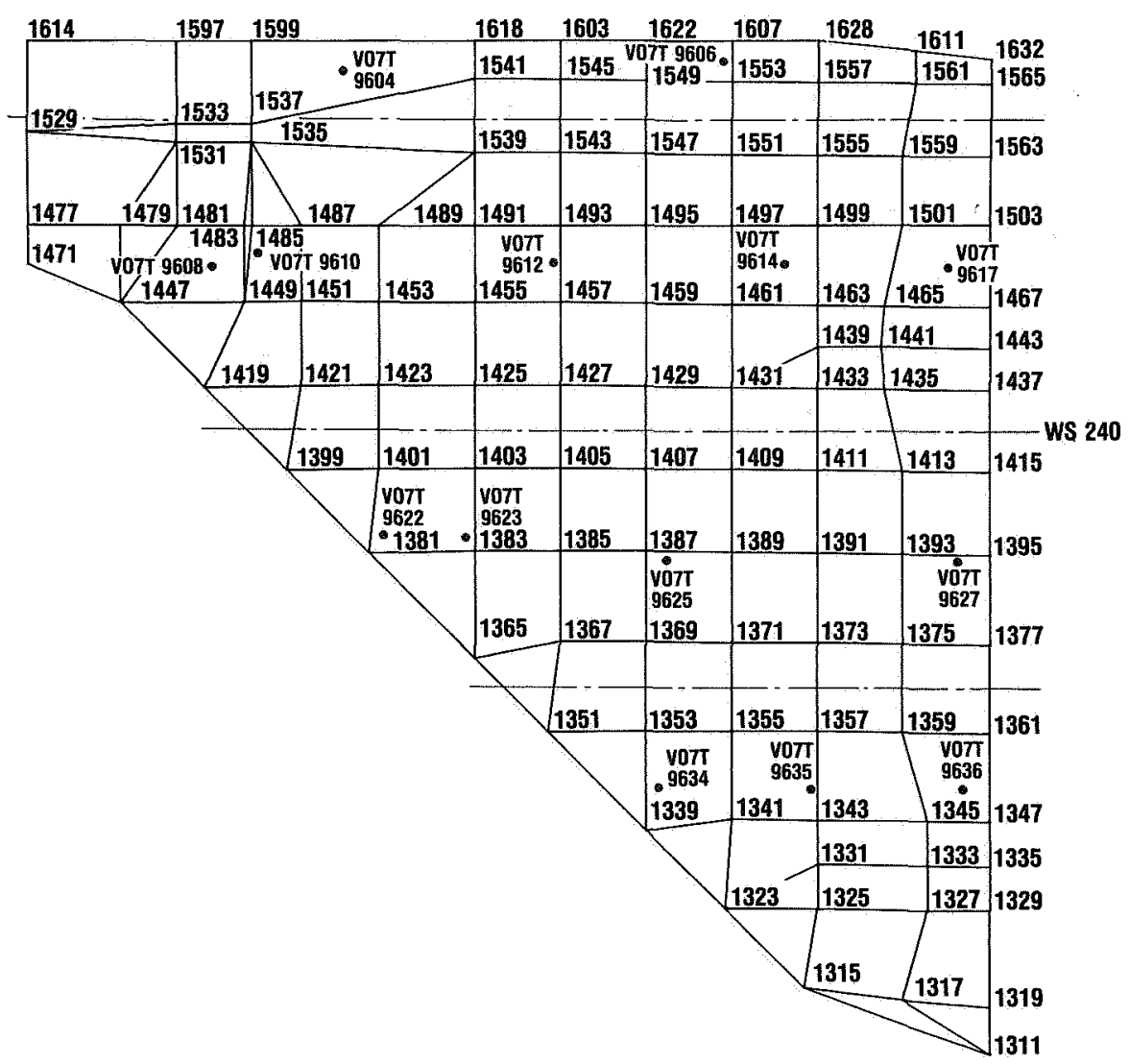

Fig. Il Wing upper TPS surface joint locations and thermocouple locations. 


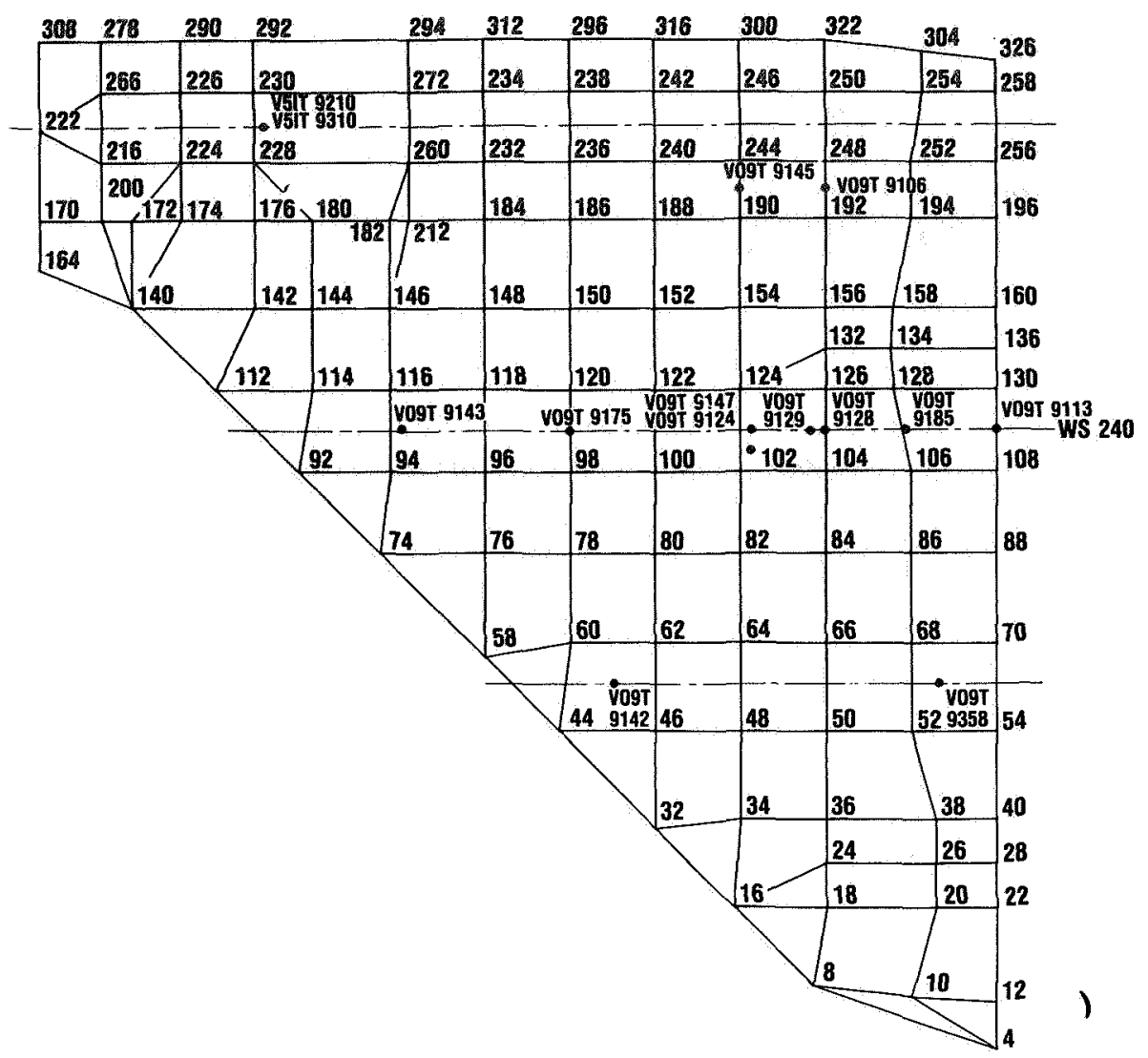

Fig. 12 Wing lower skin joint locations and thermocouple locations.

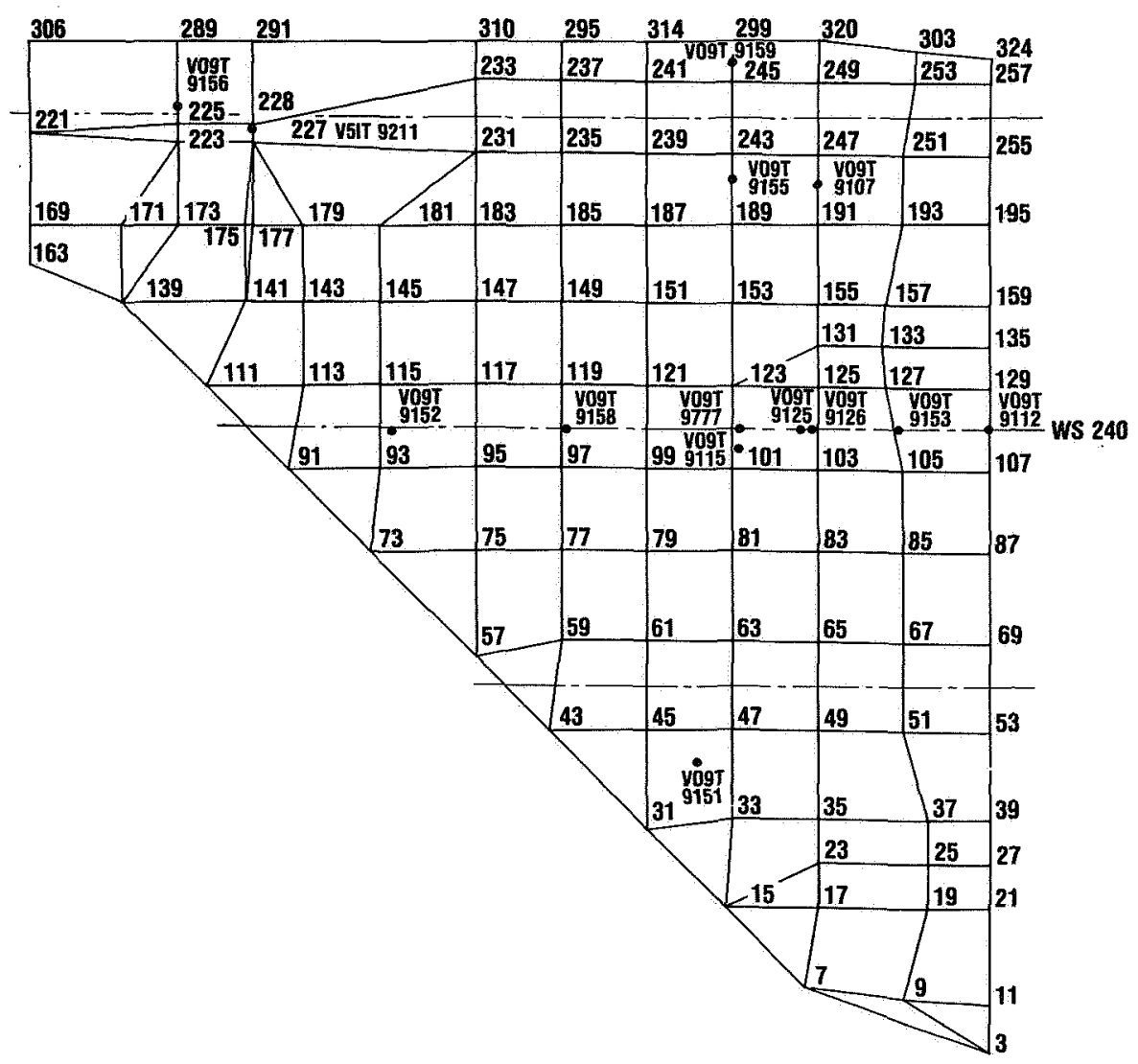

Fig. 13 Wing upper skin joint locations and thermocouple locations. 


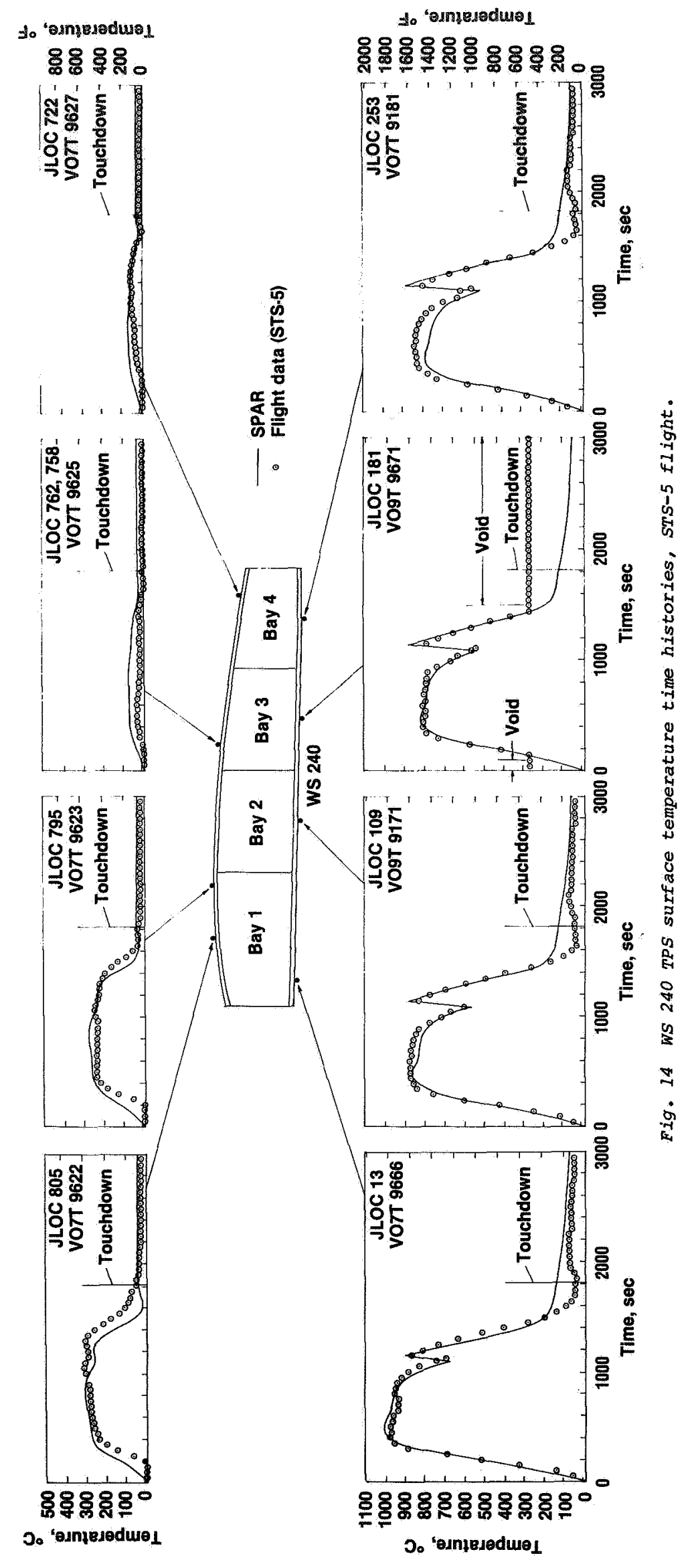




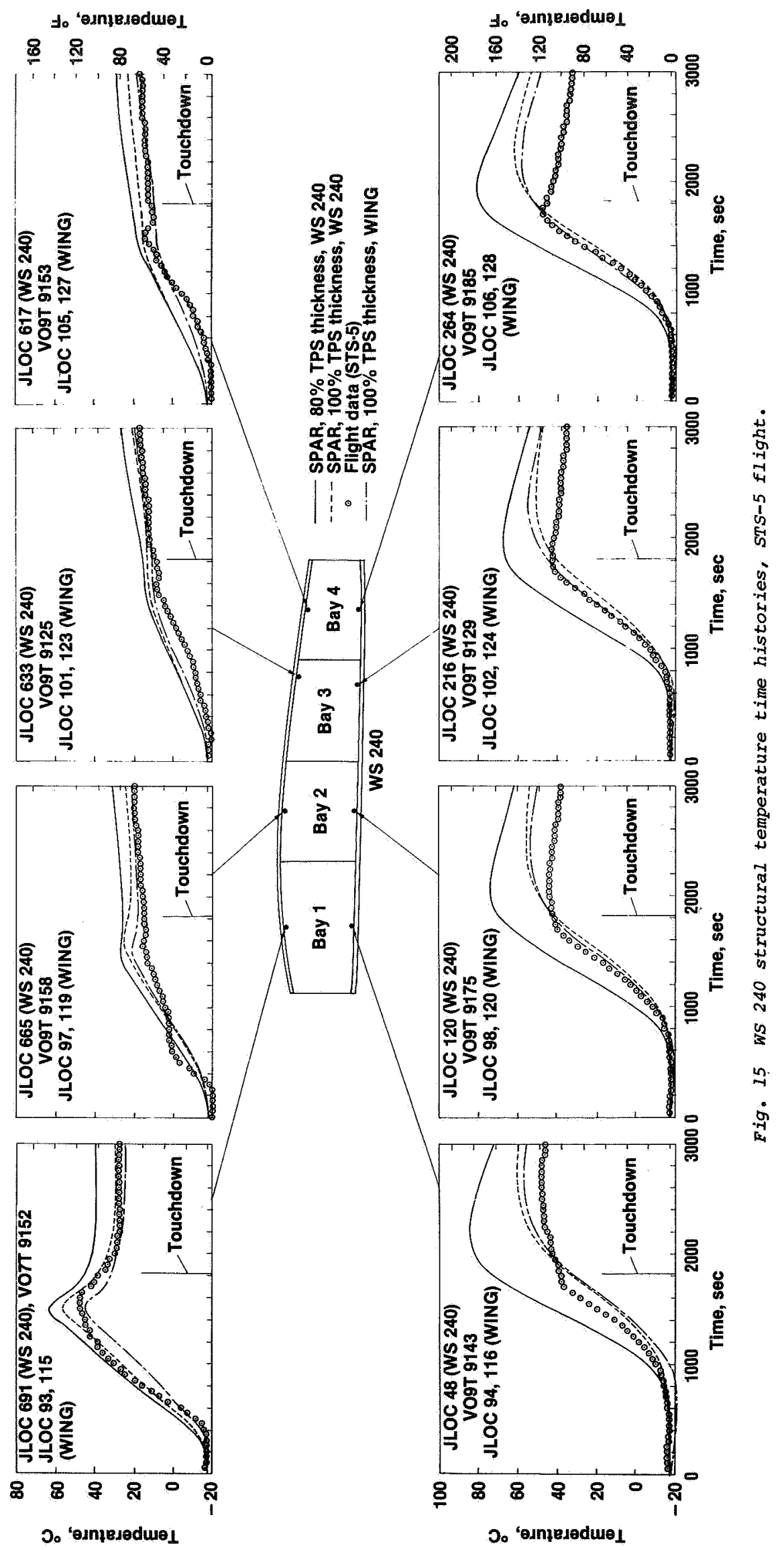



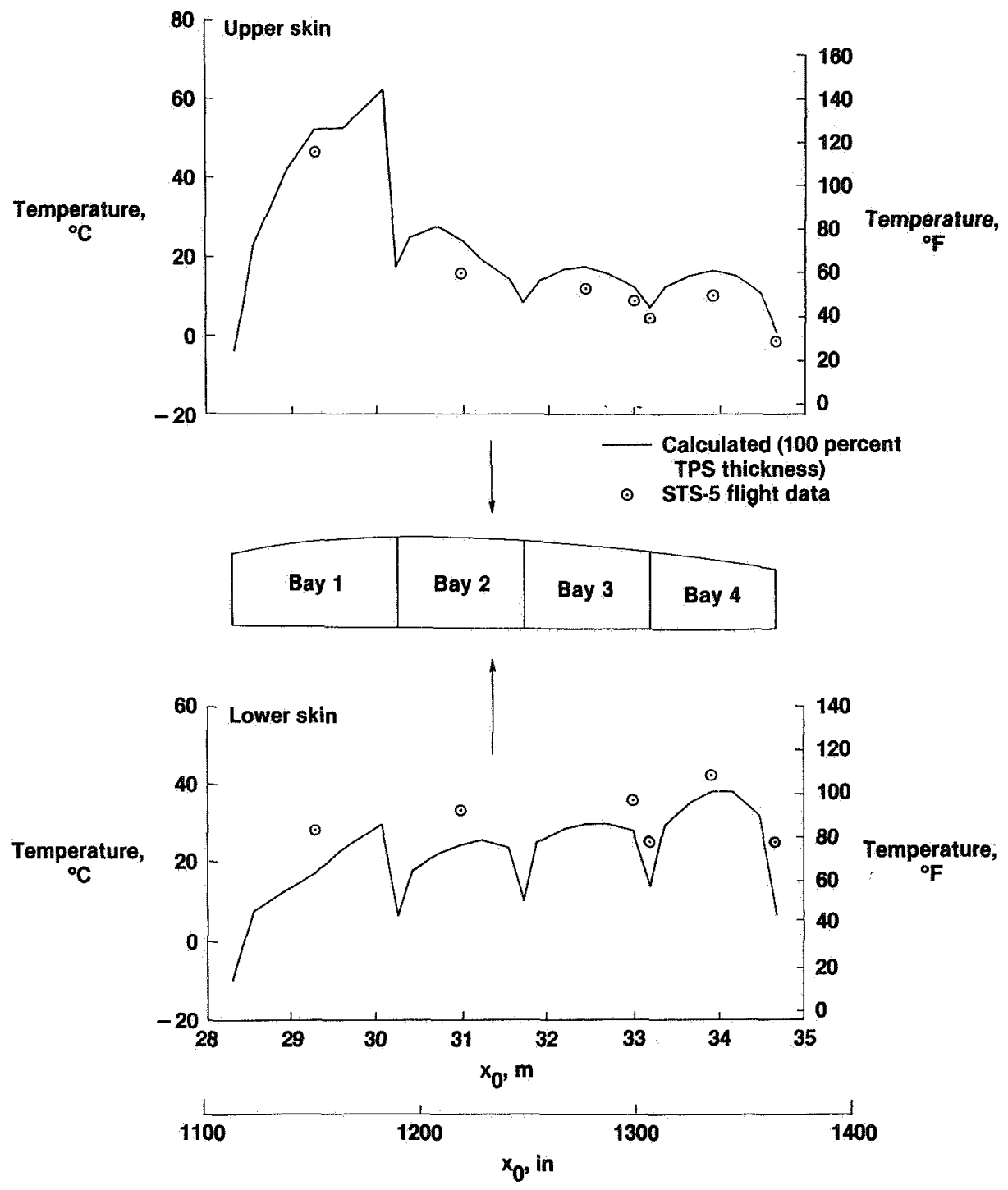

Fig. 16 WS 240 chordwise distribution of the aluminum skin temperatures for STS-5 flight; time $=1600 \mathrm{sec}$. 


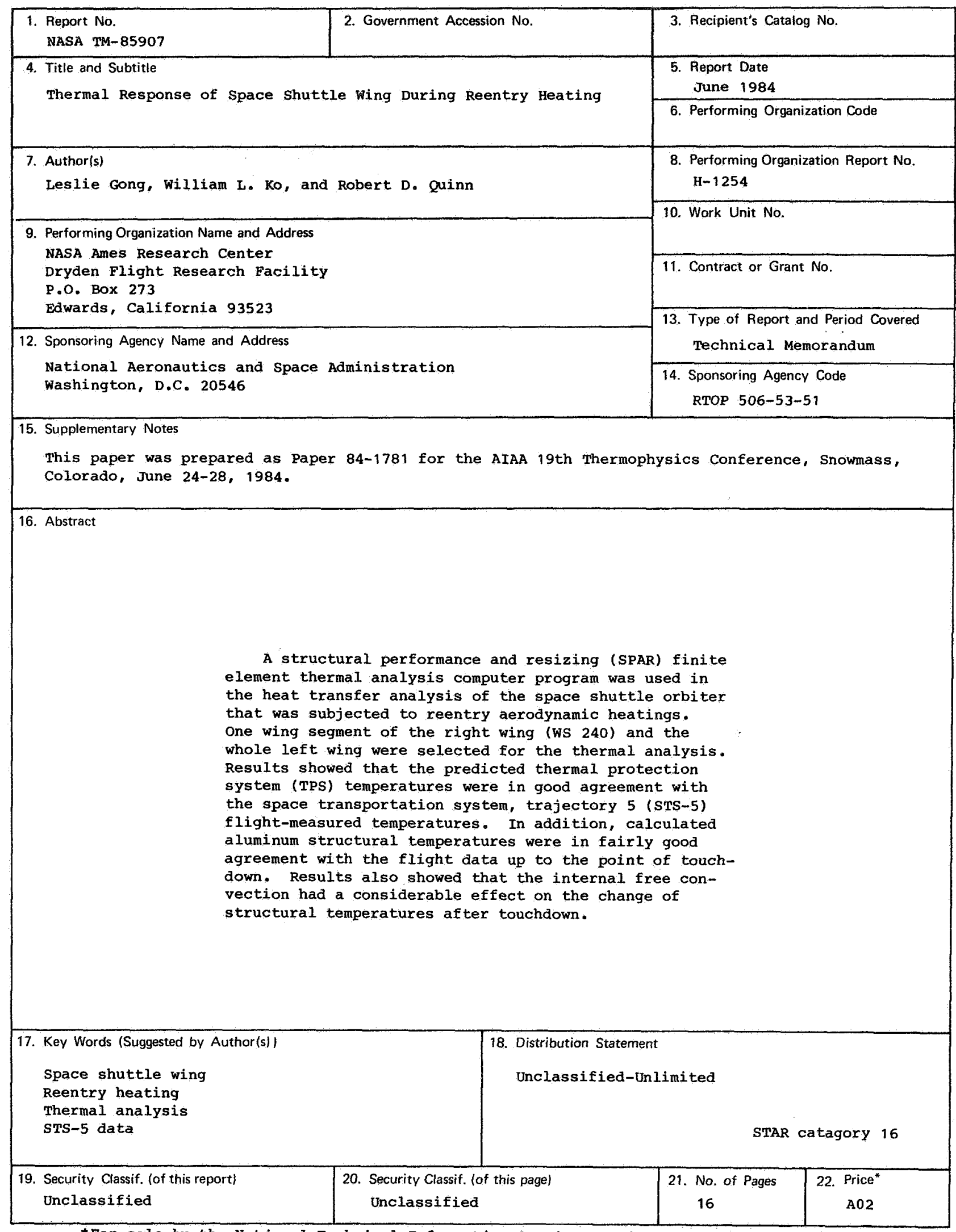

*For sale by the National Technical Information Service, Springfield, Virginia 22161. 